Relations industrielles

Industrial Relations

\title{
Cultural Foundations of Industrial Civilization, John U. Neff. Cambridge University Press. 1954, 164 pp.
}

\section{Raymond Gérin}

Volume 13, numéro 4, octobre 1958

URI : https://id.erudit.org/iderudit/1022416ar

DOI : https://doi.org/10.7202/1022416ar

Aller au sommaire du numéro

Éditeur(s)

Département des relations industrielles de l'Université Laval

ISSN

0034-379X (imprimé)

1703-8138 (numérique)

Découvrir la revue

Citer ce compte rendu

Gérin, R. (1958). Compte rendu de [Cultural Foundations of Industrial Civilization, John U. Neff. Cambridge University Press. 1954, 164 pp.] Relations industrielles / Industrial Relations, 13(4), 453-453.

https://doi.org/10.7202/1022416ar

Tous droits réservés (C Département des relations industrielles de l’Université Laval, 1958
Ce document est protégé par la loi sur le droit d'auteur. L'utilisation des services d'Érudit (y compris la reproduction) est assujettie à sa politique d'utilisation que vous pouvez consulter en ligne.

https://apropos.erudit.org/fr/usagers/politique-dutilisation/ 


\section{RECENSIONS - BOOK REVIEWS}

Cultural Foundations of Industrial Civilization, par John U. Neff. Cambridge University Press. 1954, 164 pp.

Les livres sur la genèse de la révolution industrielle sont légion. Parmi ceuxci, le livre de M. Neff aspire à sortir des sentiers battus. Il s'agit d'une synthèse des mouvements de pensée qui sont à l'origine de notre monde industriel. Ce ne pouvait être l'oeuvre que d'un humaniste profondément imprégné de culture européenne, particulièrement française. Pour écrire efficacement sur un tel sujet, il devait en être ainsi. Il le déclare d'ailleurs lui-même. Il lui fallut d'abond maîtriser les diverses disciplines de l'histoire pour écrire avec sens cet essai d'un peu plus de cent cinquante pages. Nous croyons qu'il a réussi.

Notre monde industriel, écrit-il, n'est pas le résultat fortuit de découvertes techniques, comme on l'a laissé entendre, mais d'une évolution de la pensée humaine qui a rendu possible non seulement ces découvertes, mais la nécessité de leur apparition. Du moment où l'on a commencé à penser en termes de notions exactes, de précisions quantitatives, le principe de la science découlant de l'observation et non de concepts théologiques prenait place et allait s'imposer.

Par ailleurs, la Réforme dispersait l'Eglise rendant la terre et ses ressources à une multitude d'individus, nobles ou bourgeois qui les mirent à profit pour d'autres fins économiques. D'où création de nouvelles sources de production et naissance d'une économie quantitative.

Puis la Renaissance suivit qui donna le goût du beau; ce beau, la nouvelle économie le rendait désirable et le mettait à la portée d'un plus grand nombre.

Dans le même temps, le mouvement spirituel, amorcé par ces deux saints si différents pourtant l'un de l'autre que furent François de Sales et Vincent de Paul amène l'Eglise à voir le salut des âmes non plus seulement dans da contemplation, mais dans l'oeuvre de chaque jour accompli conformément à l'enseignement du Christ.

Les obstacles à la révolution industrielle étaient disparus: imprécision de la science des techniques, désintéressement des biens terrestres, mais plutôt apparition du concept de la science valable par elle-même et naissance d'intérêts nouveaux dû à la possession privée des biens matériels. Les fondements culturels étaient posés à notre civilisation industrielle.

Le livre de John U. Neff est un essai, avec toutes les imperfections du genre; certains développements nous laissent insatisfaits. Mais il jette une lumière nouvelle sur notre origine industrielle et trace la voie à des recherches plus poussées. Déjà, cependant, il donne au lecteur un aperçu du cheminement curieux de la pensée humaine à travers les âges et son aboutissement actuel,

RaYMoND GÉRIN 